\title{
Asymptotical Stability of Riemann-Liouville Nonlinear Fractional Neutral Systems with Time-Varying Delays
}

\author{
Erdal KORKMAZ ${ }^{1}$ and Abdulhamit Ozdemir ${ }^{1}$ \\ ${ }^{1}$ Mus Alparslan University
}

November 14, 2021

\begin{abstract}
In this paper, we investigate the asymptotic stability of solutions for a class of nonlinear fractional neutral differential systems with time dependent delays when the given delays are unbounded. An example is used to show the efficacy of the theorems. The LMI tool box was used to calculate the solutions to the convex optimization problems.
\end{abstract}

\section{Hosted file}

korkmaz_and_ozdemir.pdf available at https://authorea.com/users/446086/articles/545408asymptotical-stability-of-riemann-liouville-nonlinear-fractional-neutral-systems-withtime-varying-delays 